\title{
HUMAN RIGHTS OF MENTALLY ILL PATIENTS
}

\author{
Christos Iliadis ${ }^{1}$, Aikaterini Frantzana ${ }^{2}$, Aikaterini Kourkouta ${ }^{3}$, Petros Ouzounakis ${ }^{4}$ \\ ${ }^{1} \mathrm{RN}$, Private Diagnostic Health Center of Thessaloniki, Greece \\ ${ }^{2} \mathrm{RN}$, General Hospital of Thessaloniki "Papanikolaou" Greece \\ ${ }^{3}$ Student of Department of Law, Aristotle University of Thessaloniki, Greece \\ ${ }^{4} \mathrm{RN}$, General Hospital of Alexandroupoli, Greece
}

\begin{abstract}
.
Introduction: Mental health is the development of a person's healthy view of themselves and the environment in which they live, so that they can achieve the highest degree of self-fulfillment. Purpose: The purpose of the present work is to investigate and highlight the rights of the mentally ill and to promote and promote the health of these patients. Methodology: The study material consisted of articles on the topic found in Greek and international databases such as: Google Scholar, Mednet, Pubmed, Medline and the Hellenic Academic Libraries Association (HEAL-Link), using keywords: mental illness, patient rights, health professionals. Results: The rights of mental patients and their exercise in a meaningful and effective manner is a dynamic process that encompasses the corresponding rights and obligations of mental health professionals. An important legal effort to protect the rights of the mentally ill is Resolution 46/119 of the United Nations General Assembly on the Protection of Persons with Mental Illness and Improving Mental Health Care, adopted on 17 December 1991. Conclusions: The exercise of the rights of the mentally ill requires their encouragement from mental health professionals, who are essentially obliged to refrain from restrictive practices.
\end{abstract}

Keywords: mental health, human rights, mental illness, patient rights, health professionals

\section{INTRODUCTION}

Mental health is the development of a person's healthy outlook of himself and the surroundings in which he lives, so that the individual is able to achieve the highest degree of self-fulfillment (World Health Organization, 2005). According to the World Health Organization (WHO), mental health is the total and harmonious function of a person's personality as whole. On the other side, mental disorder is the failure of the human being to adapt adequately to the demands of the society he lives in (Chamberlin, 1998)

The majority of people maintain a delicate balance between the forces exerted by those agents that allow them to lead a relatively stable life. When the balance is disturbed then, it results in stress, affecting firstly the individual himself; it causes "nervous" reactions such as anxiety or depression, often accompanied by disturbances in biological functions such as disturbed sleep or appetite disturbance. (Harding, 2000) Secondly, it has an impact on people around him, caused by so-called "antisocial behavior" and, as a result, it causes a personality disorder. The combination of both factors makes the person inappropriate, thereby 
creating stress on himself and people around him, resulting in the emergence of a mental illness. (Freeman \& Pathare, 2005)

People with psychological problems were always being confronted with even a great deal of fear by the community. In recent years, an effort has been made to provide psychiatric care while respecting the rights of the mentally ill. The knowledge of the rights of the mentally ill is a fundamental obligation of each and every mental health professional. (Grace, Fry \& Schultz, 2003)

The purpose of the present study is to investigate, highlight the rights of the mentally ill, defend and promote the health of these patients.

The study material is consisted of articles on the topic found in Greek and international databases such as: Google Scholar, Mednet, Pubmed, Medline and the Hellenic Academic Libraries Association (HEAL-Link), using the keywords: mental illness, patient rights, health professionals.

\section{Ethics and Ethical Issues while caring mentally ill patients}

When providing care to the mentally ill, ethics and ethical issues arise regarding the person providing care, the patient's family and his employer.

The keystone underlying the principles and rules of ethics in the care of the mentally ill includes (Burt \& Eklund, 2005):

sos The principle of autonomy

sos The principle of utility

sos The principle of non-harm

so The principle of justice

Every process towards treatment must strive to keep the patient's nature and function confidential as well as benefit him / her and not harm him or her or offend the legal feeling. The ethical principles that govern any handling are (Beauchamp \&Childress, 2001):

* The promotion the autonomy of human dignity

* Personalizing each person's needs

* Confidentiality of information

* Purity of communication

The family must be honestly informed of the progress or problems of their member in the field of rehabilitation in which the patient is involved. The family must be responsibly involved in the therapeutic work to the most possible and meaningful extent. (Burt \& Eklund, 2005)

The employer's case has several peculiarities. According to the law, the employer knows that he is takes on a disabled person, for his or her salary is subsidized. Limits ought to be set regarding the pieces of information regarding the employee's health only to the point in which the person's impersonal work is guaranteed. For instance, the employer is to be informed of the fact that his employee takes some psychiatric medication, but not the specific medication being applied to him. (Freeman \& Pathare, 2005)

Ethical dilemmas, such as whether patients' opinions should be respected or what the sick person thinks is right for his or her community reintegration, or what the mental health practitioner thinks is good for the patient, are involved in the design and organization of Community Reintegration (CR) via deinstitutionalization 
programs. These programs must focus on the principles above, while the clinical factor is also included; in other words, whether the condition of the patient allows for a clearer recognition and prioritization of his needs. (Szmukler, 1999)

The essential and effective exercise of individual and social rights by mental patients signifies corresponding rights and obligations for mental health professionals. (Burt \& Eklund, 2005)

\section{Mentally ill patients' rights}

The rights of mental patients and their exercise in a meaningful and effective manner is a dynamic process that encompasses the corresponding rights and obligations of mental health professionals. An important legal effort to protect the rights of the mentally ill is Resolution 46/119 of the United Nations General Assembly on the Protection of Persons with Mental Illness and Improving Mental Health Care, adopted on 17 December 1991. (Harding, 2000)

The above UN General Assembly Resolution 46/119 (1991) consists of 25 Principles concerning civil rights and procedures and access to and quality of care, which are applied without any discrimination on disability, nationality, gender, color, language, religion, political or other opinion, national, legal or social status, age or property. (Stein, 2017)The application of these principles is subject only to restrictions on the protection of the health or safety of the individual or of third parties or the protection of public safety, order, health or morals and the fundamental rights and freedoms of others.

At national level in Greece, the provisions of Constitution 1975/1986/2001, which are directly applicable and affect the entire population, irrespective of their state of health that it must not be a prerequisite for their application. (Spyropoulos \& Fortsakis, 2017)

The institutional framework of mental health in Greece today is assessed as adequate so far, as it guarantees the rights of individuals with mental disorders who are no longer within the margins of law and justice in the broader context of psychiatric reform. (Townsend, 2012)

The rights of mental patients, as well as the concurrent obligations of the State, Mental Health Units and mental health professionals, refer to titles and sections, in the sense that each of the following incorporates a number of individual rights / obligations as follows (https://www.psy.gr):

1. The right to decent care (voluntary and involuntary). It is the ability of every person diagnosed with a mental illness to reach out to providers of human mental health services and receive services that, based on scientific and medical data and assumptions, are most appropriate to the nature of their illness. (Pescosolido, Gardner \& Lubell, 1998)

2. The right to equality. The principle of equality requires equal treatment of persons who are in substantially similar conditions, as well as the equal treatment of persons who are in situations of multiple exclusion from social structures. (Fredman, 2001)

3. The right to information. Informing the patient and his family is necessary to secure their consent to treatment. (Anderson, 1996)

4. The right to the protection of personal data. Protecting the privacy of a mentally ill person is an explicit legal requirement, protected by statutory bodies, and a fundamental obligation of mental health professionals. 
5. The right to rehabilitation. Supporting the exercise of the right to participate in rehabilitation procedures should aim at self-reliance.

6. The right to community life. This right is part of and is a specialized form of the general social right to implement reintegration into society deinstitutionalization and policies towards reducing stigma and prejudices about the risk of placing mentally ill in the community. Something that requires the creation of strong alliance societies among communities. (Sartorius \& Schulze, 2005)

7. The right to claim. The individual rights of the mentally ill in Greece are protected by the provisions of Constitution 1975/1986/2001 and derive from the provision of Article 5 of the Constitution which stipulates that everyone has the right to the protection of their health and genetic identity.

Mentally ill patients and their families should be encouraged to pursue policy measures that help consolidate and strengthen their rights. (Abuse, 2013)

In conclusion, the exercise of the rights of the mentally ill presupposes their encouragement by mental health professionals, who are essentially obliged to refrain from restrictive practices. On the contrary, they have to act in a way that reinforces and supports the exercise of their rights according to reasonableness of "together" and not the reasonableness of substitution. (Tsaloglidou, $2009 \&$ Tsaousoglou \& Koukourikos, 2007)

\section{REFERENCES}

Abuse, S. (2013). Mental Health Services Administration. Results from the, 2, 013.

Anderson, R.J. (1996). A security policy model for clinical information systems. In Proceedings 1996 IEEE Symposium on Security and Privacy (pp. 3043). IEEE.

Beauchamp, T.L., \& Childress, J.F. (2001). Principles of biomedical ethics. Oxford University Press, USA.

Burt, B.A., \& Eklund, S.A. (2005). Dentistry, Dental Practice, and the Community-E-Book. Elsevier Health Sciences.

Chamberlin, J. (1998). Citizenship rights and psychiatric disability. Psychiatric Rehabilitation Journal, 21(4), 405.

Fredman, S. (2001). Equality: a new generation?. Industrial Law Journal, 30(2), 145-168

Freeman, M., \& Pathare, S. (2005). WHO resource book on mental health, human rights and legislation. World Health Organization.

Grace, P.J., Fry, S.T., \& Schultz, G.S. (2003). Ethics and human rights issues experienced by psychiatric-mental health and substance abuse registered nurses. Journal of the American Psychiatric Nurses Association, 9(1), 1723.

Harding, T.W. (2000). Human rights law in the field of mental health: a critical review. Acta Psychiatrica Scandinavica, 101(399), 24-30.

The Rights of Mentally Disabled. Available in https://www.psy.gr

Pescosolido, B.A., Gardner, C.B., \& Lubell, K.M. (1998). How people get into mental health services: Stories of choice, coercion and "muddling through" from "first-timers". Social science \& medicine, 46(2), 275-286. 
Sartorius, N., \& Schulze, H. (2005). Reducing the stigma of mental illness: a report from a global association. Cambridge University Press.

Spyropoulos, P.C., \& Fortsakis, T.P. (2017). Constitutional law in Greece. Kluwer Law International BV.

Stein, M.A. (2017). Disability human rights. In Nussbaum and Law (pp. 3-49). Routledge.

Szmukler, G. (1999). Ethics in community psychiatry. Australian and New Zealand Journal of Psychiatry, 33(3), 328-338.

Townsend, E.A. (2012). Boundaries and bridges to adult mental health: Critical occupational and capabilities perspectives of justice. Journal of Occupational Science, 19(1), 8-24.

Tsaloglidou, A. (2009). Does audit improve the quality of care? International Journal of Caring Sciences, 2 (2), 65-72.

Tsaousoglou, A., \& Koukourikos, K. (2007). Quality and health services. DROP, $15(2), 18-24$.

World Health Organization. Department of Mental Health, Substance Abuse, World Health Organization, World Health Organization. Department of Mental Health, Substance Abuse. Mental Health, World Health Organization. Mental Health Evidence, \& Research Team. (2005). Mental health atlas 2005. World Health Organization

Keywords: mental health, human rights, mental illness, patient rights, health professionals 